\title{
Disturbances in the Wind Speed Fields due to the Crimean Mountains
}

\author{
V. V. Efimov*, O. I. Komarovskaya \\ Marine Hydrophysical Institute of RAS, Sevastopol, Russian Federation \\ *vefim38@mail.ru
}

Introduction. Influence of the Crimean Mountains on the wind regime in the Crimea region for different seasons and wind directions is considered.

Data and methods. Data on the monthly average temperature values on the model levels of the ERA Interim reanalysis [10] for 40 years (1979-2018) and also the results of modeling using the regional numerical model of atmospheric circulation WRF-ARW are used.

Results. The fields of surface wind speeds in the Crimea region are considered at the northern and southern directions of the background wind which are close to the normal one in relation to the ridge. Annual variation of buoyancy frequency for the flat regions of the Crimea Peninsula and for its Southern Coast separated from them by the Crimean Mountains is given. The periods of the most probable disturbances in the surface wind fields induced by the Crimean Mountains are revealed. Using the regional atmospheric circulation model WRF-ARW, the wind speed fields for a few typical directions of the background undisturbed wind are simulated.

Discussion and conclusions. It is shown that in a spring-summer period (April-June) in the atmosphere over the sea, the conditions required to block the air flow from the south to the Crimean Mountains ridge arise. As a result, an alongshore flow is formed, and the mesoscale zone of speed perturbations springs up. At the northern winds, stable stratification in the boundary layer over the Crimea land areas is observed, on the average, throughout the whole year, except for four summerautumn months (June-September); significant wind speed disturbances can also develop. However, they are of local character, i.e. concentrated directly near the mountain ridge and over the leeward slope where the velocity disturbances of a bora type are formed in a narrow coastal zone. Repeatability statistics of these two cases of the wind speed field perturbation caused by the mountains is assessed and considered.

Keywords: Crimea region, field of surface wind speed, Crimean Mountains, Froude number, buoyancy frequency, WRF-ARW model.

Acknowledgments: the investigation was carried within the framework of the state tasks on theme No. 0827-2018-0001 "Fundamental studies of the interaction processes in the ocean-atmosphere system conditioning the regional spatial-temporal variability of natural environment and climate"

For citation: Efimov, V.V. and Komarovskaya, O.I., 2019. Disturbances in the Wind Speed Fields due to the Crimean Mountains. Physical Oceanography, [e-journal] 26(2), pp. 123-134. doi:10.22449/1573-160X-2019-2-123-134

DOI:10.22449/1573-160X-2019-2-123-134

(C) 2019, V. V. Efimov, O. I. Komarovskaya

(C) 2019, Physical Oceanography

\section{Introduction}

The Crimean Mountains are a natural barrier to the spread of airflow and can lead to significant disturbances in the fields of wind velocity and air temperature, which determine the local climate features of Crimea. In [1], the mechanism of the Crimean Mountains effect on the temperature regime of the Southern Coast of Crimea (SCC) is studied in detail. It is shown that at the winds of the northern and north-western directions in the winter period, the blocking of air flow on the northern slopes of the Crimean Mountains and its replacement on the southern 
slopes with warmer air from the upper layers of the atmosphere take place. The result is a formation of warm sub-Mediterranean climate in the SCC area. However, this effect does not limit all types of disturbances of velocity and temperature fields, which depend both on the characteristics of the background wind velocity field (on its direction and velocity magnitude), and on the temperature field vertical structure (on the buoyancy frequency). By the background wind we mean the wind outside the zone of the air flow distortion by the mountains.

In this paper, the impact of mountains on the wind and temperature regime of the Crimean region for different seasons and wind directions is considered. Using the $W R F-A R W$ regional numerical model of atmospheric circulation, we estimated the disturbances of the velocity fields introduced by the Crimean Mountains, depending on the direction of the background wind flow. The features of the seasonal variability of such disturbances are also considered.

The character of the air flow around the mountain is determined by the wind velocity and buoyancy frequency vertical profiles in the lower layer of the atmosphere at the heights comparable to the one of the mountain. Physical mechanisms of interaction of the mountain with the air flow are well studied nowadays (see, for example, review papers [2-6]). The determining parameter of the flow around regime is the Froude number, which is preset by the formula $\mathrm{Fr}=U / \mathrm{Nh}$ in the region of the atmospheric boundary layer for the heights comparable to the one of the mountain, where $U$ is the wind velocity; $h$ is the mountain height; $N$ is the buoyancy frequency related with the vertical profile potential temperature $\theta: N^{2}=\mathrm{g} \theta_{\mathrm{z}} / \theta_{0}$, here $g$ is the free fall acceleration; $\theta_{0}$ is the mean potential temperature; $\theta_{\mathrm{z}}$ is the derivative with respect to the height $z$. For indifferent stratification $N$, air particles in the near-surface layer freely move up the windward slope and then move down the leeward slope of the mountain. For a baroclinic stable atmosphere with $N>0$, the particles can only move up to $h<\sim U / F r h$ height [7]. The very character of the mountain flow around by the air flux changes when the Froude number reaches a certain critical value - a transition from the nonlinear wave mode to the breaking of internal waves occurs. In the presence of an extended mountain ridge (the Crimean Mountains) the critical value of the Froude number is close to one [3]. If the Froude number is larger than the critical one, when the mountains are flown around by the air flux a supercritical wave regime is set, if less - a subcritical regime. It leads to the break of internal waves and the formation of an intense jet flow on the leeward slope of the mountains. In the first case the disturbances develop at high altitudes, comparable to the height of the mountains, in the second case they develop from an area of low altitudes. As applied to higher wind velocities, when these velocity disturbances are defined as Bora, the first case can be defined as a deep Bora case and the second one - as a shallow Bora [8].

\section{Numerical model}

A numerical model of the atmospheric circulation $W R F-A R W$ [9], well known in the literature, was used for modeling. We briefly mention its parameters. 4 consecutively nested domains with 8100, 2700, 900, and $300 \mathrm{~m}$ resolutions, respectively, were selected, while the fourth domain with the highest resolution 
covered the area of the SCC. In the model vertical structure is represented by $39 \sigma$ levels with uneven heights (with increased resolution in the planetary boundary layer). The following options are used for the calculation in the model: RRTM and Dudhia - for balancing shortwave and longwave radiation, respectively, KainFritsch - for cumulus clouds. Phase transitions in the atmosphere were determined by the Single-Moment 3-class scheme, the parameterization of the near-surface boundary layer is specified by MM5 similarity scheme. Atmospheric boundary layer was calculated using Mellor - Yamada turbulence closure scheme in the first two domains and YSU (Yon Sei University) in the nested third and fourth domains. The input data that determines the calculation of atmospheric processes development in all domains by specifying the boundary conditions in the outer first domain is the data of operational Global Forecast System (GFS) analysis with $0.5^{\circ} \times 0.5^{\circ}$ resolution and $6 \mathrm{~h}$ time interval.

\section{Annual variation of buoyancy frequency}

The parameters of buoyancy and the wind velocity above the flat land parts of the Crimean Peninsula and the Southern Coast of Crimea, which are separated from them by the Crimean Mountains, usually significantly differ. Disturbances introduced by the ridge of the Crimean Mountains also significantly differ at the southern and northern directions of the background wind velocity.

We consider the annual variation of the buoyancy frequency for these areas. In Fig. 1 the values of buoyancy frequency $N$ obtained from the data on the monthly average values of temperature at the ERA-Interim reanalysis model levels [10] for 40 years (1979-2018) are shown. Here the annual variation estimate of the average value $N$ frequency in 10-546 m layer for two selected points is represented. The first point is located in the land area in close proximity to Simferopol; the second one is above the sea southward of Yalta.

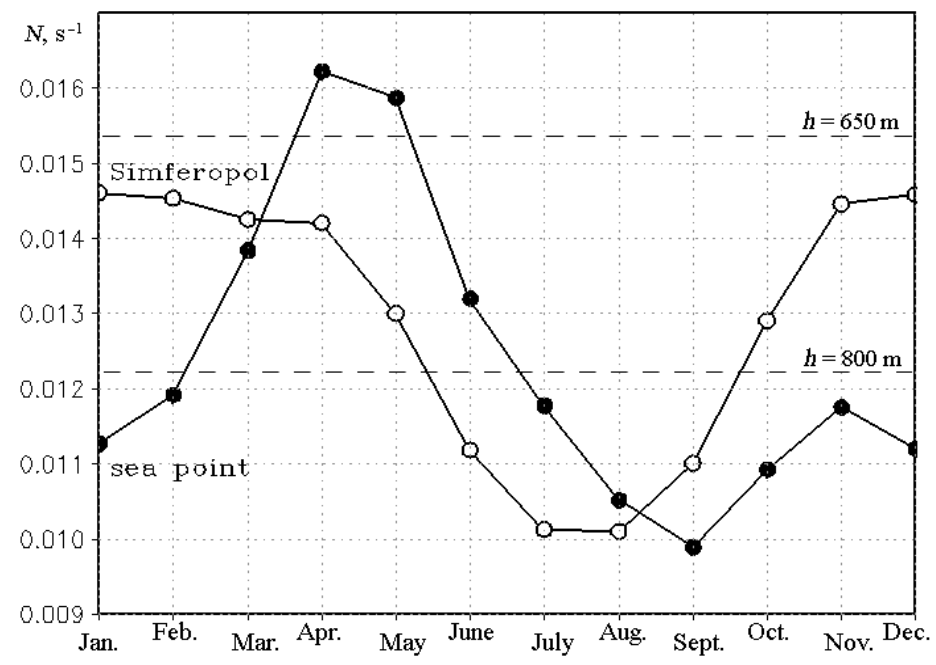

F i g. 1. Annual variation of buoyancy frequency $N$ (average over height $10-546 \mathrm{~m}$ ) at the point on land $45^{\circ} \mathrm{N}, 34^{\circ} \mathrm{E}$ (Simferopol) and at the point in the sea $43.875^{\circ} \mathrm{N}, 34.25^{\circ} \mathrm{E}$ based on ERA-Interim reanalysis data [10] for 1979-2018 
As can be seen, $N$ annual variation above the land and the sea area varies significantly. In the buoyancy frequency a well-pronounced maximum of stability related to the spring air warming above relatively cold water is observed above the sea for the April - May period. Above the land the air is stable throughout the year, except for the summer-autumn months (June - September), when daily temperatures are minimal as a result of daytime heating and the formation of a convectively unstable atmospheric boundary layer. Although $N$ data are mean daily values averaged over 40 years and the estimates for a certain observation period may differ due to synoptic variability, we can nevertheless assume that general trends of the buoyancy frequency annual variation over the sea part and the land of the Crimean region are described by Fig. 1.

Horizontal dashed lines $h=650 \mathrm{~m}$ and $h=800 \mathrm{~m}$ in Fig. 1 for the conventional wind velocity $U=10 \mathrm{~m} / \mathrm{s}$ correspond to the values of Froude number $\mathrm{Fr}=1$. Thus, $N$ values lying above these lines fall in $\mathrm{Fr}<1$ range when low-level disturbances develop for the corresponding ridge height. The area on the graphs falling in Fr > 1 range corresponds to high-level wave velocity disturbances [8].

\section{Perturbations introduced by the Crimean Mountains for different wind directions}

We consider the fields of near-surface wind for the cases of strong wind effect that are typical for the region. The cases of the north-eastern wind were selected as the most repeatable direction for the Crimean region (according to data for Simferopol, http://www.pogodaiklimat.ru/climate/33946.htm), as well as the cases of the northern, north-western and opposite southern, south-eastern winds with the directions close to normal with respect to the location of the mountains.

The wind of the southern direction. The greatest disturbances of the wind velocity field over the marine area of Crimea develop during April-June period at a wind of southern direction. They are of interest because they cover significant (up to $100-150 \mathrm{~km}$ ) parts of the sea to the south and south-west of the Crimea and are expressed in a change of background wind direction. Near the Southern Coast of Crimea the wind changes its direction to the alongshore one, and only at a considerable distance from the peninsula the background wind direction remains the same. This type of perturbation is illustrated by Fig. 2, $a$, in which for southeastern background wind case in April 2018 the wind velocity vectra at $10 \mathrm{~m}$ height and potential temperature in arbitrary units $\theta==\mathrm{K}-273.15$ are shown (for mountainous regions the use of $\theta$ temperature is more convenient for describing the surface temperature, which is close to the temperature in ${ }^{\circ} \mathrm{C}$ for the sea level). 


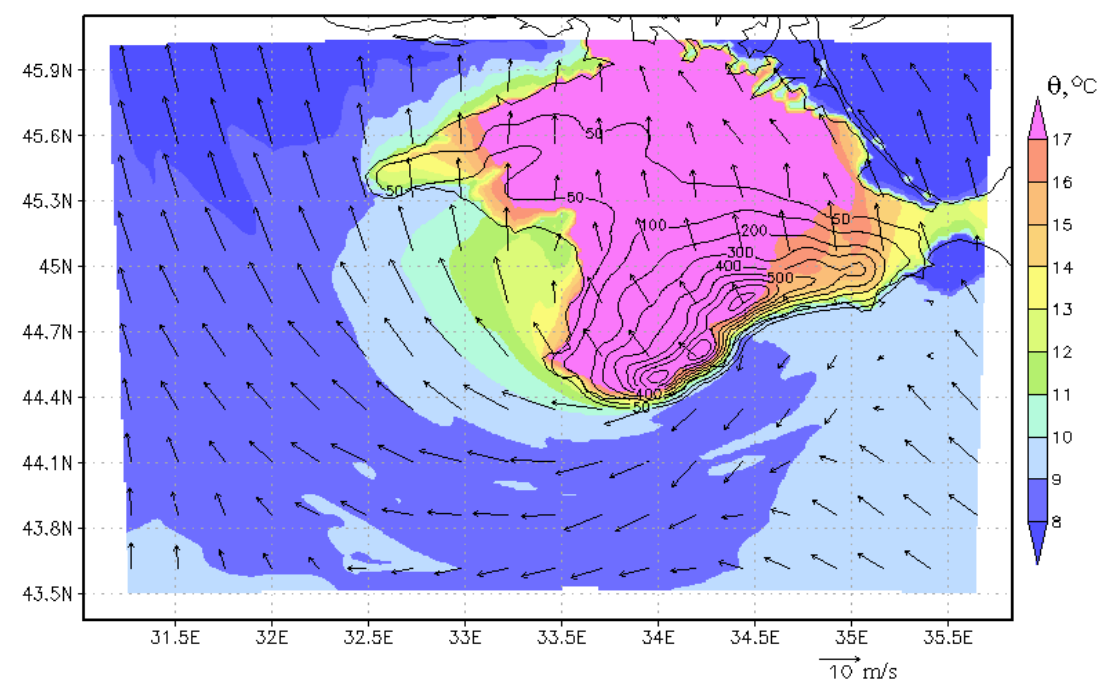

$a$

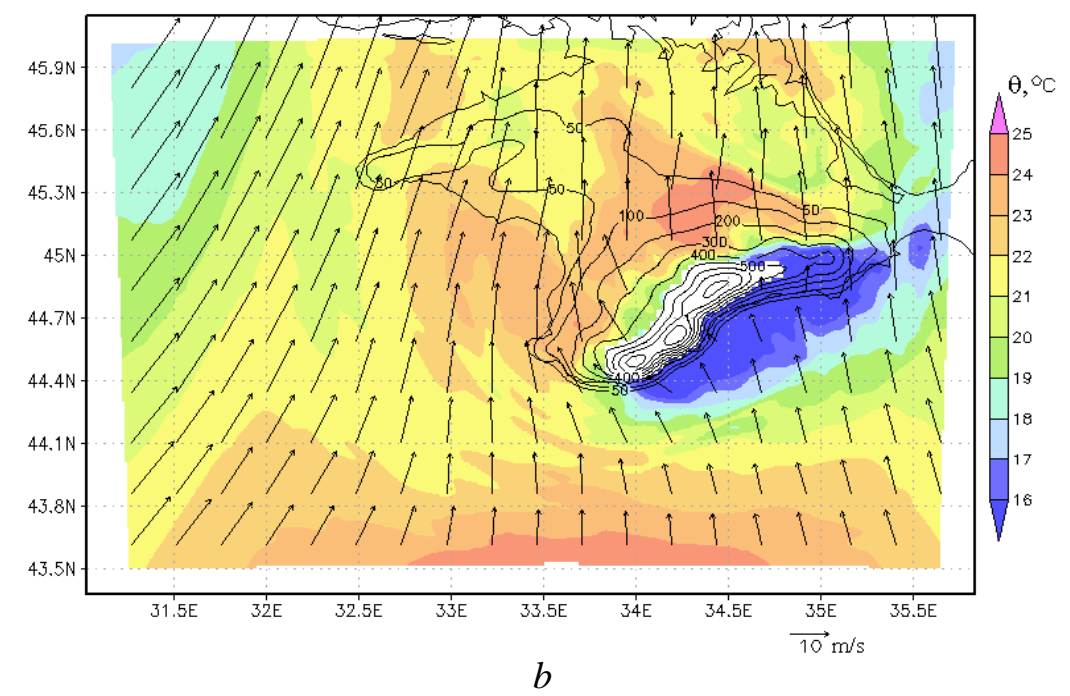

F i g. 2. Fields of wind velocity (arrows) and potential temperature (color) at the heights of $10 \mathrm{~m}(a)$ and $550 \mathrm{~m}(b)$ based on the model calculation data for 01.04 .2018 (12:00)

Physical mechanism of the formation of a vast area of wind velocity field disturbances by the mountains is explained well in Fig. 3. It shows the vertical profiles of buoyancy frequency $N$ and the velocity components - zonal $U$ and meridional $V$-in the lower part of the atmosphere. It can be seen large values of the buoyancy frequency, reaching $\sim 0.04 \mathrm{~s}^{-1}$ near the surface, and wind velocity $\sim 10 \mathrm{~m} / \mathrm{s}$. For such values $\mathrm{Fr} \sim 0.5$, i.e. when the wind flows around the mountains, the effect of wind blocking on the windward slope is significant. It limits the rise of air particles along the slope. Thus, with the velocity values averaged in the lower part of the atmosphere $\sim 10 \mathrm{~m} / \mathrm{s}$ and $N \sim 0.02-0.03 \mathrm{~s}^{-1}$, the blocking height $h_{\mathrm{b}}=V / N$ : above this height the particles of near-surface air do not move up, but spread along the windward slope in the transverse (along the ridge) direction. In our case such slope wind is directed to the west. 


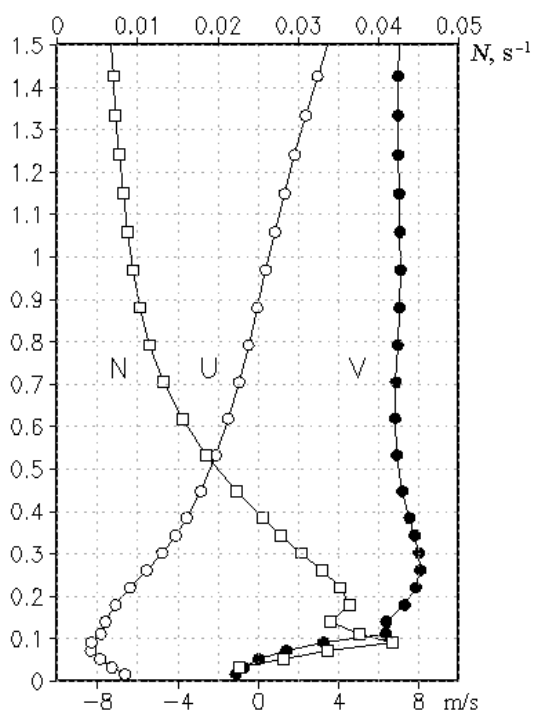

F i g. 3. Vertical profiles of zonal $(U)$ and meridian $(V)$ components of wind velocity and buoyancy frequency $(N)$ at the point in the Black Sea $43.875^{\circ} \mathrm{N}, 34.25^{\circ} \mathrm{E}$ based on the model calculation data for $01.04 .2018(12: 00)$

As can be seen from Fig. 2, $b$, for $\sim 500 \mathrm{~m}$ height the area of air flow blocking and the one of perturbations reduced to a small zone directly near the top of the mountains. The fact of occurrence of lowering by $3-4{ }^{\circ} \mathrm{C}$ areas of the potential temperature values $\theta$ above the sea in the coastal part of the SCC is also interesting. This directly indicates the moving up of the air when approaching the windward slope of a mountain ridge.

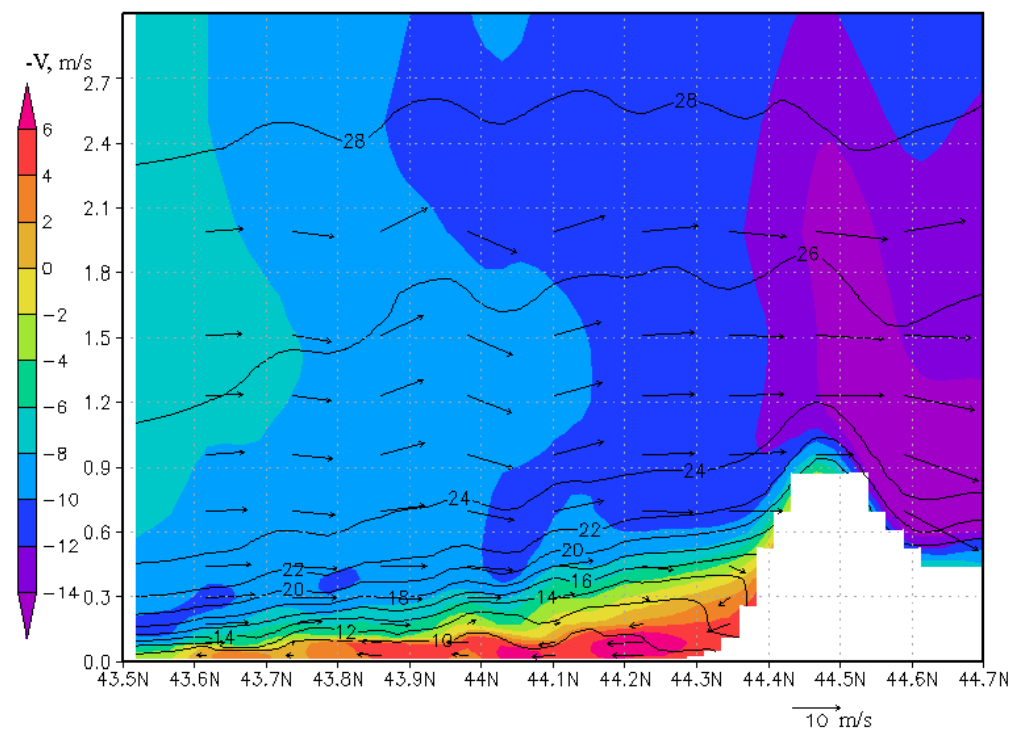

F i g. 4. Vertical structure of the wind velocity meridian component $\mathrm{V}$ (color), potential temperature $\theta$ (isolines) and velocity vectra $\{\mathrm{V}, 20 \mathrm{~W}\}$ (arrows), where $\mathrm{W}$ is vertical component on the vertical plane for zonal section along $34^{\circ} \mathrm{E}$ based on the model calculations for $01.04 .2018(12: 00)$ 
Fig. 4 shows the distribution in altitude of the velocity meridional component along a section through the high-mountain part of the ridge $\left(34^{\circ} \mathrm{E}\right)$. Perturbation area extended in longitude by more than $100 \mathrm{~km}$ and gradually decreasing in height and thickness with the distance from Crimea is represented well.

The wind of the northern direction. In Fig. 5 the velocity fields for the case of northern wind effect are represented, in Fig. 6 - the vertical profiles of buoyancy frequency and velocity components above the land, at the base of the windward slope of the mountains. Here, the air flow on a smooth windward slope is almost not blocked - it does not change its direction when approaching the top of the mountain ridge. This is due to the characteristic feature of $N$ frequency vertical profile: up to heights of $\sim 500 \mathrm{~m}$ the values $N \sim 0.01 \mathrm{~s}^{-1}$, blocking height is $\sim 800 \mathrm{~m}$. This is the main difference from the case of the wind of the southern direction, where a stably stratified air flux flows on a very steep slope of the SCC mountains.

For such a case of the background wind effect, the maximum values of the near-surface wind velocity perturbations are localized in the area of the mountain ridge leeward slope - on the scale of Fig. 5 this relatively narrow zone is not represented. The consideration of wind field detailed structure in the area of mountain ridge and the windward slope for the cases of the northern wind effect is beyond the scope of the article - it was previously described in $[1,11,12]$. In the sea coastal zone, relatively small velocity disturbances are visible. They are expressed in the changes in wind direction related to the alongshore inhomogeneities of the mountains. The velocity values in this zone are comparable with the ones of background wind velocity above the sea. It is interesting that above the land the wind velocity value is lower by $40-60 \%$, which is explained by higher values of the surface roughness parameter compared to the sea.

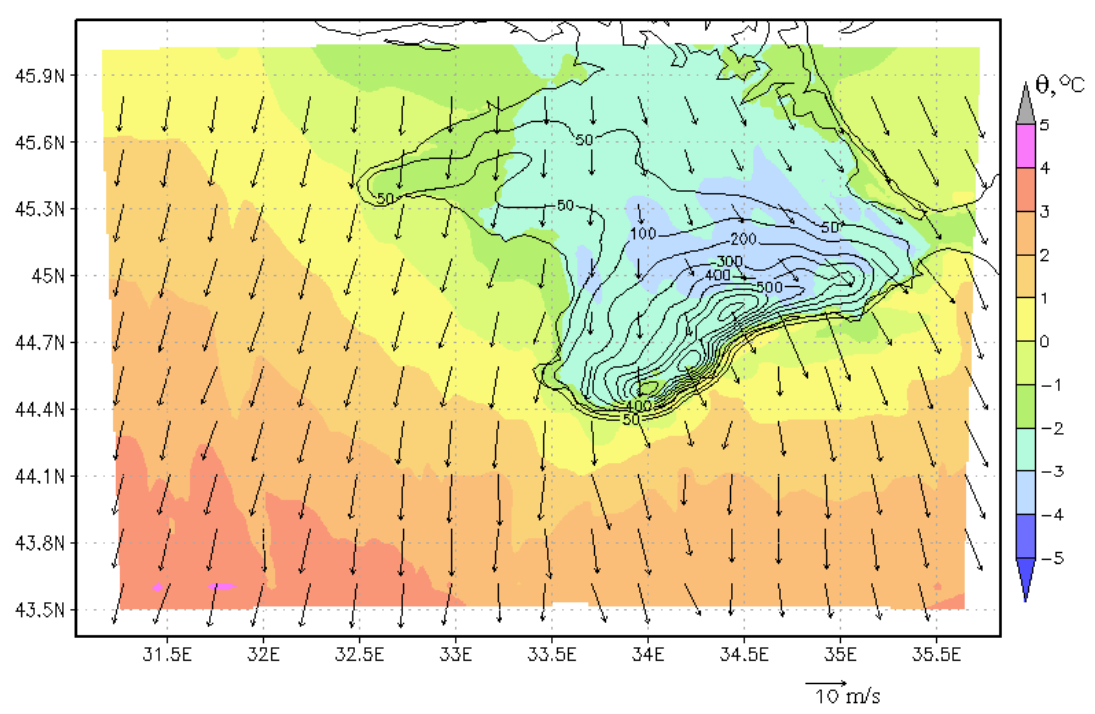

F i g. 5. Fields of wind velocity (arrows) and potential temperature (color) at $10 \mathrm{~m}$ height based on the model calculations for 03.12.2013 (10:00) 


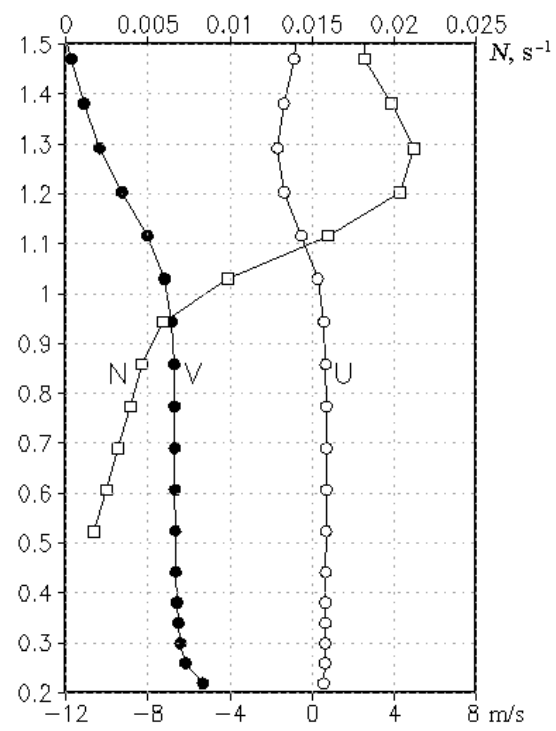

F i g. 6. Vertical profiles of zonal $(U)$ and meridional $(V)$ components of wind velocity and buoyancy frequency $(N)$ at $45^{\circ} \mathrm{N}, 34^{\circ} \mathrm{E}$ point on the land based on model calculations for 03.12.2013 (10:00)

Thus, the wind of northern direction does not cause significant mesoscale perturbations of velocity and temperature above the sea southward of Crimea even with stable stratification. At the same time, this does not apply to a relatively narrow area above the land and to the marine area near the mountains where smallscale perturbations can be significant. At high velocities of background wind intense bora-type currents of air can develop here [11,12], and the air temperature can rise by $4-6^{\circ} \mathrm{C}$ compared to the neighboring areas [1].

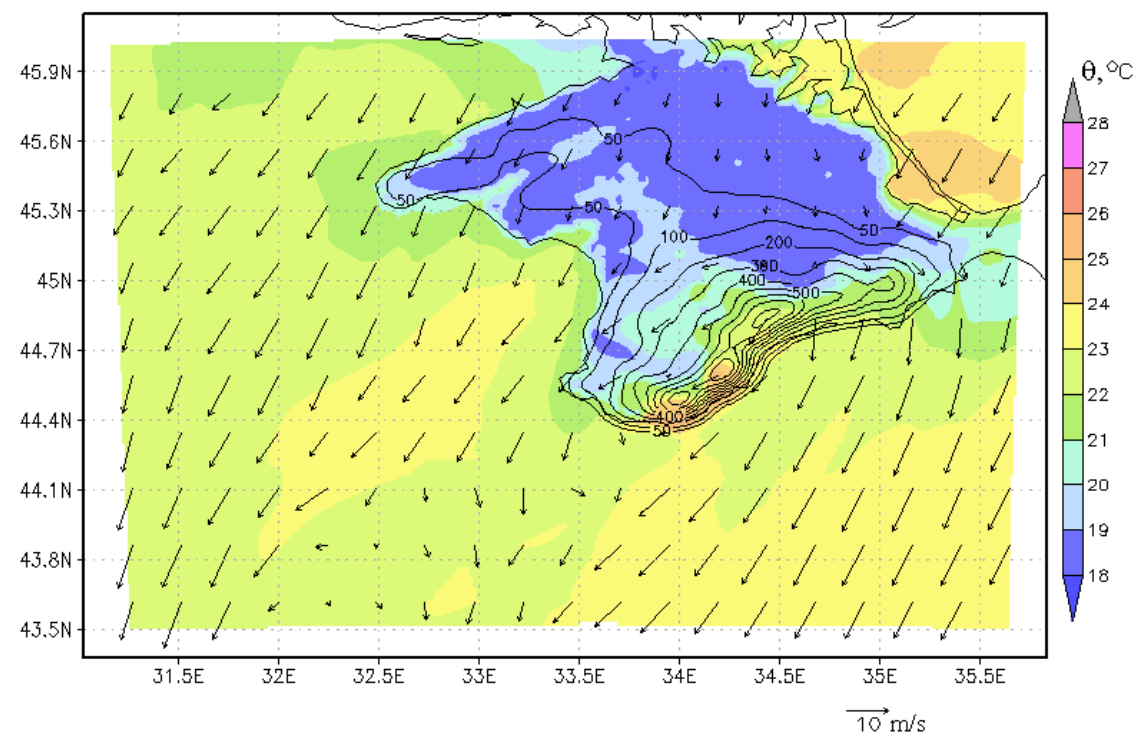

F i g. 7. Fields of wind velocity (arrows) and potential temperature (color) at $10 \mathrm{~m}$ height based on model calculations for 18.07.2017 (18:00) 
The wind of north-eastern direction. This case corresponds to the background wind directed along the slopes of the mountain ridge. In Fig. 7 the wind velocity field in the form of vectors for one of such episodes of the north-eastern wind effect is shown. In general, it can be noted that there is no significant change in the near-surface wind field in the regions on both sides of the mountain ridge. Only beyond the south-western edge of the peninsula, above the sea and beyond the ridge of high mountains eddy formations can be observed. Hydrodynamic mechanisms of such perturbations may resemble Karman tracks, but their analysis requires separate consideration.

\section{Repeatability of perturbations for the southern wind}

It is interesting to estimate the repeatability of the fulfillment of necessary conditions for the formation of wind velocity field most significant perturbations caused by mountains. These include two types of considered disturbances. At first, these are mesoscale velocity perturbations, covering the entire part of the sea, adjacent to the mountainous southern edge of Crimea, shown in Fig. 2. Secondly, these are small-scale bora-type local perturbations for the northern wind. As mentioned, for the occurrence of such low-level disturbances, a combination of a sufficiently high wind velocity of the desired direction and such values of $N$ frequency, at which the condition $\mathrm{Fr}<1$ is fulfilled, is required.

At values of $\mathrm{Fr}>1$, the perturbations are localized in the region of the leeward slope near the tops of the mountains [8]. This means that in such a case, at the southern wind, the required conditions for blocking the air flow on the slopes of the SCC mountains are not fulfilled and a vast mesoscale disturbance area is not formed.

In Fig. 8 the joint distribution of $N$ buoyancy frequency, which is average for $10-546 \mathrm{~m}$ height, and wind velocity at $\sim 910 \mathrm{~m}$ height for the northern winds at a point above the land (left parts of the figure) in the winter months (January, February) is shown. The right side of the figure shows the distribution for southern winds at the Black Sea point in the spring months (April, May). Distributions are based on temperature data (53rd and 60th model levels) and wind velocity components (51th model level) of the ERA-Interim reanalysis [10] over 40 years $(1979-2018)$ with $6 \mathrm{~h}$ time discreteness. The northern directions include the north-western ones with a deviation of no more than $75^{\circ}$ and the north-eastern with a deviation of no more than $15^{\circ}$ from the north. The southern directions include the south-western ones with a deviation of no more than $15^{\circ}$ and the south-eastern with a deviation of no more than $75^{\circ}$ from the south, which is consistent with the location of the Crimean Mountains ridge. Straight lines correspond to the Froude number $\mathrm{Fr}=1$ for $800 \mathrm{~m}$ (1), $500 \mathrm{~m}$ (2) and $300 \mathrm{~m} \mathrm{(3)}$ heights. Thus, the areas lying above these lines on the graphs correspond to lowlevel disturbance modes (at high wind velocities these are Bora areas). The regions below the straight lines correspond to the wave regimes (higher-level perturbation regimes). 


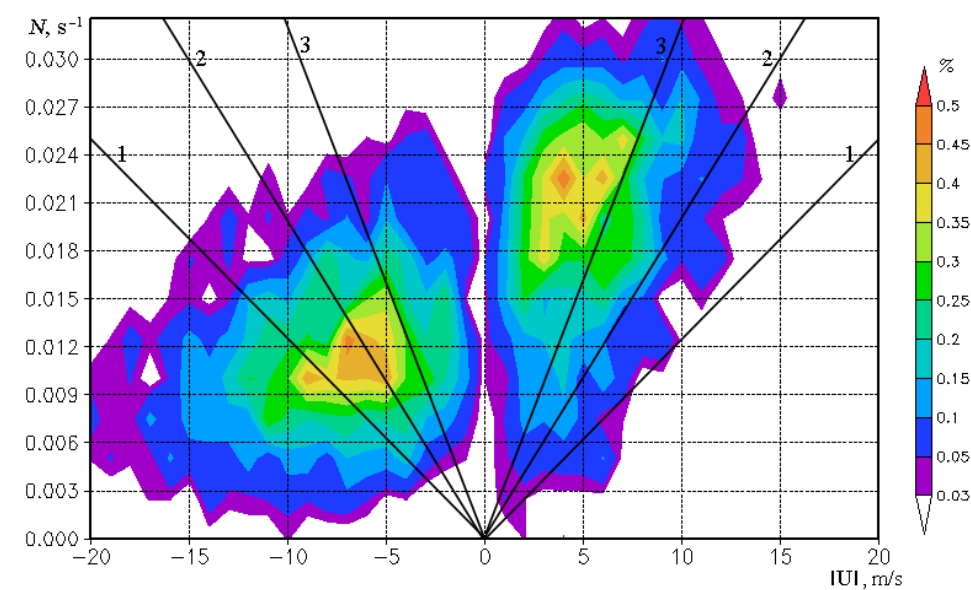

F i g. 8. Combined distribution of buoyancy frequency $N$ average over 10-546 $\mathrm{m}$ height and wind velocity at $\sim 910 \mathrm{~m}$ height based on the ERA-Interim reanalysis data for 1979-2018: to the left - for the northern winds at $45^{\circ} \mathrm{N}, 34^{\circ} \mathrm{E}$ point on the land in winter months (January, February); to the right - for the southern winds at $43.875^{\circ} \mathrm{N}, 34.25^{\circ} \mathrm{E}$ point in the Black Sea in spring months (April, May). Straight lines correspond to the Froude number $(\mathrm{Fr}=1)$ for $800 \mathrm{~m}(1), 500 \mathrm{~m} \mathrm{(2)}$ and $300 \mathrm{~m} \mathrm{(3)}$ heights

As follows from Fig. 8, the repeatability of low-level disturbances for the southern winds in the spring-summer period is noticeably higher than for the northern winds in the winter period. Repeatability values (in \% relative to the total duration of the selected periods) are given in the Table. Thus, the excitation of vast mesoscale perturbation regions of near-water wind velocity field to the south of the high Crimean Mountains still applies to rather rare cases. The cause is low frequency of southern winds in the spring-summer period [13-15].

Assessments of Bora frequency in winter (January, February) and spring (April, May) at the northern winds for $45^{\circ} \mathrm{N}, 34^{\circ} \mathrm{E}$ point and at the southern winds for the $43.875^{\circ} \mathrm{N}, 43.25^{\circ} \mathrm{E}$ point based on $E R A-I n t e r i m$ reanalysis [10] for 1979-2018

\begin{tabular}{|c|c|c|c|c|c|c|c|}
\hline $\begin{array}{l}\text { Northern } \\
\text { wind }\end{array}$ & $\begin{array}{l}\text { Height, } \\
\mathrm{m}\end{array}$ & $\begin{array}{l}\text { Regime of } \\
\text { blocking, \% }\end{array}$ & $\begin{array}{c}\text { Wave } \\
\text { regime, \% }\end{array}$ & $\begin{array}{l}\text { Southern } \\
\text { wind }\end{array}$ & $\begin{array}{l}\text { Height, } \\
\mathrm{m}\end{array}$ & $\begin{array}{c}\text { Regime of } \\
\text { blocking, \% }\end{array}$ & $\begin{array}{l}\text { Wave } \\
\text { regime, \% }\end{array}$ \\
\hline \multicolumn{4}{|c|}{ January, February } & \multicolumn{4}{|c|}{ April, May } \\
\hline \multirow{3}{*}{$\geq 5 \mathrm{~m} / \mathrm{s}$} & $\begin{array}{c}\mathrm{h}=80 \\
0\end{array}$ & 8.05 & 10.84 & \multirow{3}{*}{$\geq 5 \mathrm{~m} / \mathrm{s}$} & $\begin{array}{c}\mathrm{h}=80 \\
0\end{array}$ & 8.64 & 0.68 \\
\hline & $\begin{array}{c}\mathrm{h}=50 \\
0\end{array}$ & 3.09 & 15.80 & & $\begin{array}{c}\mathrm{h}=50 \\
0\end{array}$ & 7.16 & 2.15 \\
\hline & $\begin{array}{c}\mathrm{h}=30 \\
0\end{array}$ & 0.32 & 18.58 & & $\begin{array}{c}\mathrm{h}=30 \\
0\end{array}$ & 2.88 & 6.43 \\
\hline \multirow{3}{*}{$\geq 10 \mathrm{~m} / \mathrm{s}$} & $\begin{array}{c}\mathrm{h}=80 \\
0\end{array}$ & 0.98 & 7.19 & \multirow{3}{*}{$\geq 10 \mathrm{~m} / \mathrm{s}$} & $\begin{array}{c}\mathrm{h}=80 \\
0\end{array}$ & 1.48 & 0.28 \\
\hline & $\begin{array}{c}\mathrm{h}=50 \\
0\end{array}$ & 0.08 & 8.09 & & $\begin{array}{c}\mathrm{h}=50 \\
0\end{array}$ & 0.74 & 1.01 \\
\hline & $\begin{array}{c}\mathrm{h}=30 \\
0\end{array}$ & 0.00 & 8.18 & & $\begin{array}{c}\mathrm{h}=30 \\
0\end{array}$ & 0.00 & 1.75 \\
\hline
\end{tabular}




\section{Conclusion}

The wind above the Black Sea in coastal areas can be significantly affected by the mountains surrounding the sea. Wind disturbances induced by the high Crimean Mountains are not limited to the coastal zone of the sea in some cases, but extend over considerable distances from the coast - up to $100-150 \mathrm{~km}$. In this work, by numerical modeling using the regional model of atmospheric circulation, we reproduced the wind velocity fields for several characteristic directions of the background undisturbed wind.

It is shown that in the spring-summer period (April - June) in the atmosphere above the sea the conditions required for blocking the air flow, moving from the south to the Crimean Mountains ridge, are created. As a result, an alongshore flux is formed and a mesoscale velocity perturbation zone, which extends up to 100$150 \mathrm{~km}$ from the coast, is created.

For the case of the northern winds effect, steady stratification in the boundary layer above the land in the Crimea region is observed, on average, throughout the year, except for four summer-autumn months (June - September). At the same time, significant wind velocity perturbations may also develop. However, they are more localized: they are concentrated directly near the mountain ridge and above the leeward slope, where bora-type velocity disturbances are formed in a narrow coastal zone.

The repeatability statistics of these two cases of near-water wind velocity field disturbances caused by the presence of mountains is considered.

\section{REFERENCES}

1. Efimov, V.V. and Komarovskaya, O.I., 2018. Physical Mechanism of the Mountains Effect on Climate of the Crimean Southern Coast. Russian Meteorology and Hydrology, (in print).

2. Eckermann, S.D., Lindeman, J., Broutman, D.J., Ma, J. and Boybeyi, Z., 2010. Momentum Fluxes of Gravity Waves Generated by Variable Froude Number Flow over ThreeDimensional Obstacles. Journal of the Atmospheric Sciences, [e-journal] 67(7), pp. 22602278. https://doi.org/10.1175/2010JAS3375.1

3. Grisogono, B. and Belusšić, D, 2009. A Review of Recent Advances in Understanding the Meso- and Microscale Properties of the Severe Bora Wind. Tellus A: Dynamic Meteorology and Oceanography, [e-journal] 61(1), pp. 1-16. doi:10.1111/j.1600-0870.2007.00369.x

4. Lin, Y-L., 2007. Mesoscale Dynamic. Cambridge: Cambridge University Press, 630 p. (to appear).

5. Smith, R.B., 1989. Hydrostatic Airflow over Mountains. Advances in Geophysics, [e-journal] 31, pp. 1-41. doi:10.1016/S0065-2687(08)60052-7

6. Smith, R.B., 1985. On Severe Downslope Winds. Journal of the Atmospheric Sciences, [ejournal] 42(23), pp. 2597-2603. doi:10.1175/1520-0469(1985)042<2597:OSDW>2.0.CO;2

7. Gill, A.E., 1986. Atmosphere-Ocean Dynamics. Cambridge: Academic Press, 662 p.

8. Efimov, V.V. and Komarovskaya, O.I., 2018. Seasonal Variability and Hydrodynamic Regimes of the Novaya Zemlya Bora. Izvestiya. Atmospheric and Oceanic Physics, (in print).

9. Skamarock, W.C., Klemp, J.B., Dudhia, J., Gill, D.O., Barker, D.M., Wang, W. and Powers, J.G., 2008. A Description of the Advanced Research WRF version 3. NCAR technical note. NCAR/TN - 475+STR, [e-book] Boulder, Colorado, USA: Mesosacale and Microscale Meteorology Division National Center for Atmospheric Research, 113 p. doi:10.5065/D68S4MVH

10. Dee, D.P., Uppala, S.M., Simmons, A.J., Berrisford, P., Poli, P., Kobayashi, S., Andrae, U., Balmaseda, M.A. and Balsamo, G., et al, 2011. The ERA-Interim Reanalysis: Configuration and performance of the data assimilation system. Quarterly Journal of the Royal Meteorological Society, [e-journal] 137(656), p. 553-597. doi:10.1002/qj.828 
11. Efimov, V.V. and Barabanov, V.S., 2013. Gustiness of the Novorossiysk Bora. Russian Meteorology and Hydrology, [e-journal] 38(12), pp. 840-845. doi:10.3103/S1068373913120054

12. Efimov, V.V. and Barabanov, V.S., 2013. Black Sea Bora Modeling. Izvestiya. Atmospheric and Oceanic Physics, [e-journal] 49(6), pp. 632-641. doi:10.1134/S0001433813060066

13. Zats, V.I., Luk'yanenko, O.Ya. and Yatsevich, G.E., 1966. Gidrometeorologicheskiy Rezhim Yuzhnogo Berega Kryma [Hydrometeorological Regime of the Southern Coast of Crimea]. Leningrad: Gidrometeoizdat, 120 p. (in Russian).

14. Logvinova, K.T. and Barabash, M.B., eds., 1982. Klimat $i$ Opasnyye Gidrometeorologicheskiye Yavleniya Kryma [Climate and Dangerous Hydrometeorological Phenomena of the Crimea]. Leningrad: Gidrometeoizdat, 318 p. (in Russian).

15. Ved', I.P., 2000. Klimaticheskiy Atlas Kryma [Climate Atlas of Crimea]. Simferopol: Tavriyaplyus, 118 p. (in Russian).

About the authors:

Vladimir E. Efimov - Head of Atmosphere and Ocean Interaction Department, Marine Hydrophysical Institute of RAS (2 Kapitanskaya Str., Sevastopol, 299011, Russian Federation), Dr.Sci (Phys.-Math.), Professor, ResearcherID: P-2063-2017, Scopus Author ID: 6602381894, vefim38@mail.ru

Olga I. Komarovskaya - Research Associate, Marine Hydrophysical Institute of RAS (2 Kapitanskaya Str., Sevastopol, 299011, Russian Federation), ResearcherID: G-1814- 2019, komarovskaya@mhi-ras.ru

Contribution of the co-authors:

Vladimir E. Efimov - statement of the problem, interpretation of the results

Olga I. Komarovskaya - numerical modeling

All the authors have read and approved the final manuscript.

The authors declare that they have no conflict of interest. 